\title{
Seleção de genótipos de Dendrobium (Orchidaceae) na fase de propagação in vitro
}

\section{Genotypes selection of Dendrobium (Orchidaceae) in vitro propagation phase}

\author{
Ricardo Tadeu de Faria ${ }^{1 *}$; Anileda Paula Rossi de Moura Vicente²; \\ Thais Martins Marques Costa²; Inês Cristina de Batista Fonseca ${ }^{3}$; \\ Geraldo Lopes da Silva ${ }^{4}$; Lúcia Sadayo Assari Takahashi ${ }^{5}$
}

\section{Resumo}

O processo de hibridação artificial em orquídeas é utilizado para obtenção de novas variedades. O trabalho teve como objetivo a seleção de genótipos de Dendrobium favoráveis à propagação in vitro em escala comercial através de cruzamentos e autofecundações de plantas matrizes selecionadas. Foram utilizadas 15 plantas com características contrastantes de coloração, tamanho das flores e altura da planta; as flores polinizadas artificialmente e as sementes germinadas in vitro em meio MS, com metade da concentração dos macronutrientes. Foram realizados os cruzamentos: D9 x D7; D11 x Df22; D6 x D15; D9 x D2; D16 x D15; D5 x D9; D14 x D7; D7 x D14; D4 x D9; D6 x D9; D3 x D8; e as autofecundações: Df22; D7; D5; D21; D2; D15; D8; D23; D3 e D6. As plantas resultantes do cultivo foram avaliadas para as características: altura da planta, número de raízes, peso das massas fresca e seca total. Os melhores resultados para as características analisadas foram observados nos cruzamentos D9 x D7; D11 x Df22; D6 x D15; D16 x D15 e D14 x D7, e nas autofecundações Df22 e D7.

Palavras-chave: Dendrobium, hibridação, propagação in vitro, cultura de tecidos.

\begin{abstract}
The process of artificial hibridization in orchids is used to obtain new varieties. The objective of the present paper was to select genotypes of Dendrobium favourable for in vitro propagation for commercial utilization through crossings and self polinization of selected matrice plants. Fifteen different plants with contrasting colors, flower sizes and plant heighs were used; the flowers were artificially polinated and the seeds germinated in vitro on MS medium, with half concentration of nutrients. The following crossings were made D9 x D7; D11 x Df22; D6 x D15; D9 x D2; D16 x D15; D5 x D9; D14 x D7; D7 x D14; D4 x D9; D6 x D9; D3 x D8; and the self polinizations: Df22; D7; D5; D21; D2; D15; D8; D23; D3 and D6. The obtained
\end{abstract}

\footnotetext{
1 Professor Adjunto do Departamento de Agronomia na Universidade Estadual de Londrina. Fone/Fax: (43) $3371-4697$. Email: faria@uel.br

2 Acadêmica de Agronomia da UEL

3 Eng ${ }^{\mathrm{a}}$ Agr, ${ }^{\mathrm{a}}$ Dra , Professora Adjunta do Departamento de Agronomia da UEL

4 Técnico do Laboratório de Fitotecnia do Departamento de Agronomia da UEL

5 Eng $^{a}$ Agra, Doutoranda, Professora Adjunta do Departamento de Agronomia da UEL.

* Autor para correspondência
} 
plants were avaluated for: plant heigh, number of roots, fresh and dry matter weight. The best results was observed in the following crosses D9 x D7; D1 1 x Df22; D6 x D15; D16 x D15 and D14 x D7 and for self polinizations Df22 and D7.

Key words: Dendrobium, hibridization, in vitro propagation, tissue culture.

\section{Introdução}

A família Orchidaceae é uma das maiores entre as Angiospermas, constituída por cerca de 700 gêneros e 30.000 espécies diferentes. As orquídeas são encontradas em estado nativo em todos os continentes e nos mais variados climas, com exceção das regiões polares e de desertos extremamente secos. São abundantes nas regiões quentes e úmidas crescendo nos troncos das árvores, nas folhas em decomposição do chão das florestas, nas rochas das montanhas, nos cerrados e campos secos e quentes. Nos países de clima temperado predominam as terrestres e nos de clima quente as epífitas e as rupícolas (MILLER; WARREN, 1996).

As orquídeas do gênero Dendrobium são originárias da Índia, podendo ser encontradas na Ásia tropical e subtropical, prolongando-se para leste até as ilhas Fiji e sul da Austrália, com mais de 1500 espécies. O florescimento deste gênero ocorre geralmente na primavera, muitas delas necessitando de baixas temperaturas, no mínimo $10^{\circ} \mathrm{C}$ durante uma semana, para a indução do florescimento (SUTTLEWORTH et al., 1994).

A hibridação de orquídeas realizada de forma artificial em casa de vegetação visa a produção de cultivares de interesse comercial que apresentem alto vigor, grande número de flores e variabilidade de cores (PRAKASH; GOH, 1996). Segundo Davidson (1994), a hibridação do gênero Dendrobium é realizada para propiciar a floração precoce, estender a época de floração, expandir o número de flores, cores e formas.

Para a obtenção de linhagens puras do gênero Dendrobium há necessidade de um longo período, assim, é comum no melhoramento genético o cruzamento e autofecundação entre híbridos selecionados, visando à obtenção de novos cultivares.
Através da hibridação é possível a obtenção de sementes viáveis, tanto de cruzamentos interespecíficos quanto de cruzamentos intergenéricos taxonomicamente afins (KERBAUY, 1995).

Muitos trabalhos de hibridação tem sido realizados, assim existem mais espécies híbridas do que naturais. Isso ocorre devido à dificuldade que a planta encontra para propagar no meio ambiente natural, devido à depredação do seu habitat e à especificidade de fecundação (LUDUVIG, 1993).

Para a propagação de orquídeas em larga escala é fundamental a seleção de genótipos e o estabelecimento de meios de cultura adequados para a sua germinação e crescimento em condições de laboratório (KERBAUY, 1995; ARDITTI; ERNEST, 1990).

A propagação in vitro de Dendrobium nobile, visando a otimização da multiplicação, foi realizada por vários pesquisadores, principalmente com o objetivo de selecionar os meios de cultura adequados (INTUWONG; SAGAWA, 1975; SAGAWA; SHOJ, 1967; KUKULCZANKA; WOJCIECHOWSKA, 1983). Santinder e Sarma (1997) observaram que o meio de cultura mais adequado para a propagação in vitro de Dendrobium foi o MS (MURASHIGE; SKOOG, 1962) utilizando a metade da concentração dos macronutrientes e acrescido com $1 \mathrm{gL}^{-1}$ de carvão mineral.

O presente trabalho teve por objetivo a seleção de genótipos de Dendrobium favoráveis para a propagação in vitro, resultantes de cruzamentos e autofecundações de plantas matrizes selecionadas.

\section{Material e Métodos}

As plantas matrizes de Dendrobium nobile Lindl. (Orchidaceae) utilizadas nesse trabalho vieram de produtores da Holambra e selecionadas de acordo 
com características comerciais como coloração, número de flores, porte da planta, época de florescimento e tamanho das flores. Foram utilizadas 14 plantas de Dendrobium nobile e uma planta de Dendrobium fimbriatum Hook (Df22) para a realização dos cruzamentos e autofecundações, identificadas como: D2, D3, D4, D5, D6, D7, D8, D9, D11, D14, D15, D16, D21, Df22 e D23.

As plantas foram polinizadas artificialmente, e, após nove meses, obtidas as cápsulas contendo as sementes dos cruzamentos e autofecundações (Tabela 1). As sementes foram germinadas em meio de cultura MS (MURASHIGE; SKOOG, 1962) com a metade da concentração dos macronutrientes. cinco repetições para cada genótipo, totalizando 25 plântulas por tratamento. A inoculação das plântulas foi realizada em câmara de fluxo laminar. Os frascos foram etiquetados e vedados com filme de PVC e mantidos em ambiente com fotoperíodo de 16 horas de luz (lâmpada fluorescente) e temperatura de $22^{\circ} \mathrm{C}$ durante cinco meses.

As características avaliadas foram: altura da planta, número de raízes, peso das massas fresca e seca.

Os dados obtidos para altura das plantas, número de raízes, peso das massas fresca e seca foram submetidos à análise de variância e a comparação entre as médias pelo teste de Tukey a $5 \%$ de probabilidade.

\section{Resultados e Discussão} Dendrobium. Londrina, 2001.

\begin{tabular}{|c|c|c|}
\hline Cruzamentos & Autofecundações & \\
\hline D9 x D7 & D2 & $\bar{q}$ \\
\hline D11 x Df22 & D3 & . \\
\hline D6 x D15 & D5 & \\
\hline D9 x D2 & D6 & \\
\hline D16 x D15 & D7 & $i$ \\
\hline D5 x D9 & D8 & $\lambda$ \\
\hline D14 x D7 & D15 & \\
\hline D7 x D14 & D21 & \\
\hline D4 x D9 & Df22 & $\mathrm{a}$ \\
\hline D6 x D9 & D23 & $c$ \\
\hline D3 x D8 & & \\
\hline
\end{tabular}

A partir dos dados obtidos foi possível verificar que os melhores resultados para as características altura da planta, número de raízes, peso da matéria fresca e peso da matéria seca durante a propagação in vitro ocorreram nos cruzamentos: D9 x D7; D11 x Df22; D6 x D15; D16 x D15 e D14 x D7 com médias de crescimento em altura de $5,33 \pm 0,62 \mathrm{~cm} \mathrm{e}$ autofecundações: Df22 e D7 com médias de crescimento de 4,51 $\pm 0,09 \mathrm{~cm}$ (Tabela 2).

Para a variável altura, os maior valores foram observados nos cruzamentos D9 x D7 $(6,10 \pm 2,79 \mathrm{~cm})$ e D11 x Df22 $(6,00 \pm 1,67 \mathrm{~cm})$, embora não tenham diferido estatisticamente dos cruzamentos D6 x D15, D9 x D2, D16 x D 15, D5 x D9, D14 x D7 e D7 x D14, e o menor no cruzamento D3 x D8 com 3,53 $\pm 1,26 \mathrm{~cm}$. Nas autofecundações, as maiores alturas ocorreram nas plantas D7 $(4,42 \pm 1,52 \mathrm{~cm})$ e Df22 $(4,60 \pm 1,29 \mathrm{~cm})$ e a menor na planta D6 $(2,38 \pm 0,55 \mathrm{~cm})$ (Tabela 2). 
Faria, R. T. et al.

Tabela 2. Valores médios de altura da planta, número de raízes, peso da matéria fresca e peso da matéria seca das progênies dos cruzamentos e autofecundações de plântulas de Dendrobium após cinco meses do início do experimento. Londrina, 2001.

\begin{tabular}{llccc}
\hline Genótipos & Altura (cm) & Número de raízes & $\begin{array}{c}\text { Peso da matéria } \\
\text { fresca (g) }\end{array}$ & $\begin{array}{c}\text { Peso da matéria } \\
\text { seca(g) }\end{array}$ \\
\hline D9 x D7 & $6,10 \mathrm{a}$ & $5,20 \mathrm{abc}$ & $1,09 \mathrm{abcd}$ & $0,08 \mathrm{abc}$ \\
D11 x Df2 & $6,00 \mathrm{a}$ & $8,45 \mathrm{a}$ & $1,95 \mathrm{a}$ & $0,12 \mathrm{a}$ \\
D6 x D15 & $5,25 \mathrm{ab}$ & $8,10 \mathrm{ab}$ & $1,73 \mathrm{ab}$ & $0,11 \mathrm{ab}$ \\
D9 x D2 & $5,00 \mathrm{abc}$ & $6,05 \mathrm{abc}$ & $0,95 \mathrm{bcd}$ & $0,07 \mathrm{abc}$ \\
D16 x D15 & $4,69 \mathrm{abcd}$ & $7,25 \mathrm{abc}$ & $1,88 \mathrm{a}$ & $0,12 \mathrm{a}$ \\
D5 x D9 & $4,66 \mathrm{abcd}$ & $4,85 \mathrm{abc}$ & $0,84 \mathrm{bcd}$ & $0,08 \mathrm{abc}$ \\
D14 x D7 & $4,61 \mathrm{abcd}$ & $5,40 \mathrm{abc}$ & $1,37 \mathrm{abc}$ & $0,09 \mathrm{abc}$ \\
Df2 & $4,60 \mathrm{abcd}$ & $8,50 \mathrm{a}$ & $1,08 \mathrm{abcd}$ & $0,07 \mathrm{abc}$ \\
D7 x D14 & $4,44 \mathrm{abcd}$ & $3,15 \mathrm{bc}$ & $1,33 \mathrm{abc}$ & $0,09 \mathrm{abc}$ \\
D7 & $4,42 \mathrm{abcd}$ & $8,65 \mathrm{a}$ & $1,27 \mathrm{abcd}$ & $0,09 \mathrm{abc}$ \\
D5 & $4,08 \mathrm{bcde}$ & $8,70 \mathrm{a}$ & $1,07 \mathrm{abcd}$ & $0,07 \mathrm{abc}$ \\
D21 & $3,91 \mathrm{bcde}$ & $3,87 \mathrm{abc}$ & $0,78 \mathrm{~cd}$ & $0,05 \mathrm{abc}$ \\
D4 x D9 & $3,90 \mathrm{bcde}$ & $5,30 \mathrm{abc}$ & $0,89 \mathrm{bcd}$ & $0,06 \mathrm{abc}$ \\
D6 x D9 & $3,79 \mathrm{bcde}$ & $4,25 \mathrm{abc}$ & $0,85 \mathrm{bcd}$ & $0,06 \mathrm{abc}$ \\
D2 & $3,74 \mathrm{bcde}$ & $4,30 \mathrm{abc}$ & $1,35 \mathrm{abc}$ & $0,09 \mathrm{abc}$ \\
D15 & $3,68 \mathrm{bcde}$ & $8,30 \mathrm{ab}$ & $1,33 \mathrm{abc}$ & $0,08 \mathrm{abc}$ \\
D3 x D8 & $3,53 \mathrm{bcde}$ & $5,93 \mathrm{abc}$ & $1,25 \mathrm{abcd}$ & $0,07 \mathrm{abc}$ \\
D8 & $3,41 \mathrm{bcde}$ & $7,55 \mathrm{abc}$ & $0,79 \mathrm{~cd}$ & $0,05 \mathrm{abc}$ \\
D23 & $3,12 \mathrm{cde}$ & $4,25 \mathrm{abc}$ & $0,82 \mathrm{bcd}$ & $0,06 \mathrm{abc}$ \\
D3 & $2,90 \mathrm{de}$ & $2,80 \mathrm{c}$ & $0,75 \mathrm{~cd}$ & $0,04 \mathrm{bc}$ \\
D6 & $2,38 \mathrm{e}$ & $4,25 \mathrm{abc}$ & $0,41 \mathrm{~d}$ & $0,03 \mathrm{c}$ \\
\hline & DMS $=1,89$ & $\mathrm{DMS}=0,15$ & $\mathrm{DMS}=0,92$ & $\mathrm{DMS}=0,07$ \\
\hline & $\mathrm{CV}=16 \%$ & $\mathrm{CV}=32 \%$ & $\mathrm{CV}=30 \%$ & $\mathrm{CV}=35 \%$ \\
\hline
\end{tabular}

Médias seguidas de mesma letra na coluna não diferem entre si significativamente pelo teste de Tukey a $5 \%$ de probabilidade.

O crescimento em altura do cruzamento D9 $\mathrm{x}$ D7 $(6,10 \pm 2,79 \mathrm{~cm})$ comparativamente a autofecundação D6 $(2,38 \pm 0,55 \mathrm{~cm})$, mostrou uma grande diferença para essa característica (Tabela 2).

O cruzamento interespecífico D11 x Df22 apresentou os melhores resultados para todas as características analisadas. Ghoshal (1997), também, obteve sementes viáveis nos cruzamentos interespecificos entre Dendrobium crepidatum, Dendrobium transparense e Dendrobium pierardii.

Em Dendrobium é comum a esterilidade em cruzamentos interespecificos e autofecundações. Johansen (1990) observou que $72 \%$ das 1700 polinizações realizadas foram incompatíveis. No melhoramento genético de orquídeas, além dos cruzamentos interespecificos e intraespecifico, também foram realizados com sucesso hibridizações intergenéricas do gênero Vanda com o gênero Arachis (LEE et al., 1995).

No cruzamento recíproco das plantas D14 e D7, não houve diferenças significativas para as variáveis analisadas, não tendo sido constatada herança citoplasmática (Tabela 2).

As progênies derivadas dos cruzamentos e autofecundações apresentaram homogeneidade para as variáveis analisadas dentro de cada repetição. Os genótipos que apresentaram os melhores resultados para todas as variáveis analisadas são os mais indicados, nas condições estabelecidas, para a propagação in vitro em escala comercial. 


\section{Conclusão}

Os cruzamentos D9 x D7; D11 x Df22; D6 x D15; D16 x D15 e D14 x D7 e as autofecundações Df22 e D7 foram os mais favoráveis para a propagação in vitro de Dendrobium.

\section{Referências}

ARDITTI, J.; ERNEST, R. Micropropagation of orchids. New York: John Wiley \& Sons, 1990.

DAVIDSON, B. Dendrobium breeding trends. American Orchid Society Bulletin, West Palm Beach, v.63, p.638645, 1994.

GOSHAL, K. K. Genetic improvement of ornamental plants. Journal of Interacademicia, Cambridge, v.1, p.1-6, 1997.

INTUWONG, O.; SAGAWA, Y. Clonal propagation of Dendrobium golden wave and other nobile types. American Orchid Society Bulletin, West Palm Beach, v.28, p.319-322, 1975.

JOHANSEN, B. Incompatibility in Dendrobium (Orchidaceae). Botanical Journal of the Linnean Society, London, v.103, p.165-196, 1990.

KERBAUY, G. B. Biofábrica de orquídeas. In: GERALD, L. T. S. (Ed.). Biofábrica produção industrial de plantas "in vitro". Araras: UFSCar, 1995. p.22-24.

KUKULCZANKA, K.; WOJCIECHOWSKA, U. Propagation of two Dendrobium species by "in vitro" culture. Acta Horticulture, The Hague, n.131, p.105-111, 1983.
LEE, Y. H.; VAINSTEIN, A.; WEISS, D. Intergeneric hybridization in vandaceous orchid breeding. Ornamental plant improvement: classical and molecular approaches. In: EUCARPIA SYMPOSIUM, SECTION ORNAMENTALS, 17., Tel Aviv, Israel, 5-9 March. Acta Horticulture, The Hague, n.420, p.129-131, 1995.

LUDUVIG, M. M. Orquídeas: belas, valiosas e fáceis de cultivar. A Granja, Porto Alegre, n.538, p.58-62, 1993.

MILLER, D.; WARREN, R. Orquídeas do alto da serra da Mata Atlântica pluvial do sudeste do Brasil. São Paulo: Salamandra, 1996.

MURASHIGE, T.; SKOOG, F. A revised medium of rapid growth and bioassay with tobacco tissue cultures. Physiologia Plantarum, Copenhagen, n.15, p.473-479, 1962.

PRAKASH, L. C. L.; GOH, C. J. In vitro propagation of commercial orchids: an assessment of current methodologies and development of a novel approach thin section culture. Journal of the Orchid Society of India, Bangalore, v.10, p.31-41, 1996.

SAGAWA, Y.; SHOJ, T. Clonal propagation of Dendrobium through shoot meristem culture. American Orchid Society Bulletin, West Palm Beach, v.36, p.856-859, 1967.

SANTINDER, K.; SARMA, C. M. Selection of best medium for in vitro propagation of Dendrobium lindleyi Steud. Advancing Frontiers of Plant Sciences, New Delhi, v.10, p.1-5, 1997.

SUTTLEWORTH, F. S.; HEBERT, S. Z.; GORDON, W. D. Orquídeas: guia dos orquidófilos. 5.ed. Rio de Janeiro: Expressão e Cultura, 1994. 
